\title{
Paraplegia
}

\section{Long-Term Follow-Up of Patients with Sacral Anterior Root Stimulator Implants}

\author{
G. S. Brindley, MD, FRCP, Hon FRCS, FRS, D. N. Rushton, MD, FRCP \\ MRC Neurological Prostheses Unit, Institute of Psychiatry, De Crespigny Park, \\ London, $U K$.
}

\section{Summary}

The first 50 patients to receive a sacral anterior root stimulator for bladder control were reviewed by questionnaire in mid-1989. At that time, the follow-up period varied from 5 to 11 years, and 48 of the group were alive; 2 had died from unrelated causes. Forty-one used their implants regularly for micturition and of these, 37 were always or usually continent. Twenty-nine reported no symptomatic urinary infections in the previous year, and only 4 had 3 infections or more. Twenty-seven used their implant to assist defaecation, and 13 of 32 male users reported full implant-driven erections.

Side effects are minor, except for stimulus evoked pain sensation, which prevents use of the implant in 3 of the 7 non-users. Two of the other non-users were awaiting repair of their implant faults.

Key words: Stimulator; Implant; Micturition; Defaecation; Erection.

The first sacral anterior root stimulators for long-term bladder control were implanted into baboons in $1971 .^{1-3}$ The first human patient received her implant in 1976 , and the second and third both in $1978.4,5$

About 300 sacral anterior root stimulators designed in the MRC Neurological Prothesis Unit have now been implanted. Recent references include 6, 7, and 8.

Sacral anterior root stimulators of a different kind have been implanted in San Francisco since $1982 .{ }^{9}, 10$ The first 50 patients to receive implants designed in the MRC Neurological Prosthesis Unit were reviewed in $1985 .{ }^{11}$ We here describe the state of these first 50 patients. Two have died, both from causes unrelated to the urinary tract. To the remaining 48 we sent questionnaires in March and April 1989, and by September 47 of them had replied. The one who has not replied (patient of 35 of Table) was last seen by us in August 1988. She was not then using her implant, and she is entered in the text and tables (almost certainly correctly) as still not using it.

For all patients we have some information, and for some a great deal, that is independent of their answers to the questionnaires. 


\section{Results}

The table gives basic information about all 50 patients, and much of the follow-up information. The serial numbers correspond to those in Table I of reference 11.

Table

\begin{tabular}{|c|c|c|c|c|c|c|c|c|}
\hline $\begin{array}{l}\text { Serial } \\
\text { number }\end{array}$ & Sex & $\begin{array}{c}\text { Age } \\
\text { at } \\
\text { operation }\end{array}$ & $\begin{array}{l}\text { Level } \\
\text { of } \\
\text { lesion }\end{array}$ & $\begin{array}{l}\text { Use for } \\
\text { micturition }\end{array}$ & $\begin{array}{l}\text { Urinary } \\
\text { continence }\end{array}$ & $\begin{array}{l}\text { Use for } \\
\text { defaecation }\end{array}$ & $\begin{array}{c}\text { Erection } \\
\text { by } \\
\text { implant }\end{array}$ & $\begin{array}{l}\text { Implant } \\
\text { failures }\end{array}$ \\
\hline 1 & $\mathrm{~F}$ & 24 & MS & $\mathrm{N}$ & CATH & $\mathrm{N}$ & & 78 \\
\hline 2 & M & 38 & T6 & $\mathrm{Y}$ & $\mathrm{NN}$ & $\mathrm{N}$ & $P$ & 79 \\
\hline 3 & $M$ & 38 & $\mathrm{~T} 12$ & $\mathrm{Y}$ & YY & Y & $\mathrm{N}$ & $80,84,87$ \\
\hline 4 & $M$ & 33 & T9 & $\mathrm{Y}$ & UY & $\mathrm{Y}$ & $\mathrm{N}$ & $80,81,82$ \\
\hline 5 & M & 43 & C6 & $\mathrm{Y}$ & YYQ & $\mathrm{Y}$ & $\mathrm{N}$ & 0 \\
\hline 6 & $M$ & 28 & T10 & $\mathrm{Y}$ & YYQ & $\mathrm{N}$ & $\mathrm{N}$ & 83 \\
\hline 7 & $\mathrm{~F}$ & 41 & $\mathrm{~T} 8 \mathrm{inc}$ & - & - & - & & 0 \\
\hline 8 & $M$ & 32 & T5 & $\mathrm{N}$ & NN & $\mathrm{N}$ & $\mathrm{N}$ & 0 \\
\hline 9 & $M$ & 24 & $\mathrm{~T} 7$ & $(\mathrm{~N})$ & NN & $\mathrm{Y}$ & $\mathrm{N}$ & 0 \\
\hline 10 & $M$ & 24 & T6 & (N) & YY & $\mathrm{N}$ & $\mathrm{N}$ & 84 \\
\hline 11 & $M$ & 27 & C6 inc & $\mathrm{Y}$ & NN & $\mathrm{N}$ & $\mathrm{N}$ & 0 \\
\hline 12 & $\mathrm{~F}$ & 26 & $\mathrm{C} 6$ & $\mathrm{Y}$ & YY & $\mathrm{Y}$ & & 88 \\
\hline 13 & M & 24 & $\mathrm{C} 7$ & $\mathrm{Y}$ & NN & $\mathrm{Y}$ & $P$ & 88 \\
\hline 14 & $M$ & 41 & $\mathrm{~T} 12$ & $\mathrm{Y}$ & UU & $\mathrm{Y}$ & $\mathrm{N}$ & 0 \\
\hline 15 & $M$ & 37 & T6 & $\mathrm{Y}$ & NN & $\mathrm{N}$ & $\mathrm{N}$ & 0 \\
\hline 16 & $\mathrm{~F}$ & 21 & T3 & $\mathrm{Y}$ & YY & $\mathrm{Y}$ & & 87 \\
\hline 17 & $M$ & 28 & T10 & $\mathrm{Y}$ & UY & $\mathrm{N}$ & YY & 87 \\
\hline 18 & $M$ & 27 & T6 & $\mathrm{Y}$ & YYQ & $\mathrm{N}$ & YY & 0 \\
\hline 19 & $M$ & 33 & $\mathrm{~T} 3$ & $\mathrm{Y}$ & YYQ & $\mathrm{Y}$ & $\mathrm{N}$ & 0 \\
\hline 20 & $M$ & 36 & C7 inc & $\mathrm{Y}$ & UU & $\mathrm{Y}$ & $\mathrm{N}$ & 0 \\
\hline 21 & $M$ & 41 & C7 inc & $\mathrm{Y}$ & YYQ & $\mathrm{Y}$ & $\mathrm{Y}$ & 0 \\
\hline 22 & $\mathrm{~F}$ & 29 & T3 & Y & YY & $\mathrm{N}$ & & $83,85,87$ \\
\hline 23 & M & 22 & $\mathrm{~T} 7$ & $\mathrm{Y}$ & UU & $\mathrm{Y}$ & $\mathrm{Y}$ & 88 \\
\hline 24 & M & 24 & T5 & $\mathrm{Y}$ & YY & $\mathrm{N}$ & $\mathrm{N}$ & 0 \\
\hline 25 & M & 26 & $\mathrm{C} 7$ & Y & UY & $\mathrm{N}$ & $\mathrm{N}$ & 89 \\
\hline 26 & $\mathrm{~F}$ & 57 & MS & Y & UU & $\mathrm{Y}$ & & 0 \\
\hline 27 & M & 36 & C6 & $\mathrm{Y}$ & NN & $\mathrm{Y}$ & YY & 0 \\
\hline 28 & M & 32 & T4 inc & $\mathrm{Y}$ & YYQ & $\mathrm{Y}$ & YY & 88 \\
\hline 29 & M & 32 & T4 & $\mathrm{Y}$ & NN & $\mathrm{Y}$ & YY & 84 \\
\hline 30 & M & 41 & T4 & $\mathrm{Y}$ & YU & Y & $P$ & 0 \\
\hline 31 & M & 33 & $\mathrm{~T} 10 \mathrm{inc}$ & $\mathrm{Y}$ & YY & $\mathrm{N}$ & $\mathrm{N}$ & 0 \\
\hline 32 & M & 19 & C6 & $\mathrm{Y}$ & YY & $\mathrm{N}$ & YY & 0 \\
\hline 33 & M & 20 & $\mathrm{~T} 4$ inc & $\mathrm{Y}$ & YY & $\mathrm{Y}$ & YY & 0 \\
\hline 34 & M & 24 & $\mathrm{~T} 4$ & $\mathrm{Y}$ & YY & $\mathrm{N}$ & YY & 0 \\
\hline 35 & $\mathrm{~F}$ & 24 & L2 inc & $\mathrm{N}$ & CATH & $\mathrm{N}$ & & 0 \\
\hline 36 & $\mathrm{~F}$ & 43 & $\mathrm{~T} 10$ & $\mathrm{Y}$ & UY & $\mathrm{Y}$ & & 0 \\
\hline 37 & M & 43 & T3 & $\mathrm{Y}$ & YYQ & $\mathrm{Y}$ & $\mathrm{N}$ & 0 \\
\hline 38 & $\mathrm{~F}$ & 31 & T7 & $\mathrm{Y}$ & UU & $\mathrm{Y}$ & & 0 \\
\hline 39 & $\mathrm{~F}$ & 57 & T7 & $\mathrm{Y}$ & UU & $\mathrm{Y}$ & & 0 \\
\hline 40 & $\mathbf{M}$ & 46 & T9 inc & - & - & - & - & 87 \\
\hline 41 & $\mathbf{M}$ & 25 & T9 & Y & YYQ & $\mathrm{Y}$ & YY & 85,87 \\
\hline 42 & $\mathrm{~F}$ & 27 & T5 inc & Y & UU & Y & & 0 \\
\hline 43 & M & 20 & C7 & Y & YY & $\mathrm{N}$ & $\mathrm{Y}$ & 0 \\
\hline 44 & M & 43 & T12 & Y & UU & $\mathrm{Y}$ & $\mathrm{N}$ & 0 \\
\hline 45 & $\mathbf{M}$ & 33 & T8 & $\mathrm{N}$ & YY & $\mathrm{N}$ & $\mathrm{N}$ & 0 \\
\hline 46 & $\mathbf{M}$ & 24 & T6 & $\mathrm{Y}$ & NN & $\mathrm{Y}$ & $\mathrm{N}$ & 0 \\
\hline 47 & $\mathrm{~F}$ & 56 & T11 & $\mathrm{Y}$ & YYQ & $\mathrm{N}$ & & 0 \\
\hline 48 & $\mathbf{M}$ & 24 & T9 & $\mathrm{Y}$ & YYQ & $\mathrm{N}$ & $\mathrm{N}$ & 86,88 \\
\hline 49 & $\mathbf{M}$ & 22 & $\mathrm{~T} 2 \mathrm{inc}$ & $\mathrm{N}$ & UU & $\mathrm{N}$ & $\mathrm{N}$ & 0 \\
\hline 50 & $\mathbf{M}$ & 25 & T9 & Y & YY & Y & YY & 0 \\
\hline
\end{tabular}




\section{Necropsies}

Patient 7 died from suicide in 1983 after using the implant for $3 \frac{1}{2} 2$ years. The kidneys and bladder were macroscopically normal, the trapped spinal roots were histologically normal and free from visible platinum, and the electrodes were uncorroded.

Patient 40 died from myocardial infarction in 1989 after using the implant for 5 years. The bladder showed mild trabeculation and the ureters and renal calyces minimal dilatation. All the trapped roots were histologically normal and free from platinum, but the secondary sheaths of the S3 and S4 roots contained traces of platinum close to the corresponding cathodes, and these cathodes were slightly corroded at the free corners and edges, where one would expect current densities to be highest. The loss of platinum from them was estimated by eye at less than $0 \cdot 1 \%$, i.e. less than $0.016 \mathrm{mg}$ from each. It was too small to be detected by weighing, since new electrodes vary over a range of $+2 \%$ in weight.

\section{Implant use}

Of the 48 surviving patients, 41 (indicated by $\mathrm{Y}$ in Column 5 of Table) regularly use their implants for micturition. Five do not and it is probable (patients 8, 35, 45, 49) or certain (patient 1) that they will not in the future. Two (patients 9 and 10) are not using them at present, but used them very successfully in the past and intend to use them again. Changes since 1985 (besides the death of patient 40) are that patients 23 and 46, who were then not using their implants, now use them, that the implants of patients 9 and 10, which were then in use, are now temporarily unused, and that patient 8 ceased to use his implant in 1987 and seems unlikely to resume use.

\section{Continence}

The questions asked were:

Are you continent (dry) between bladder emptyings?

By day? Yes ...... No ...... Usually ......

By night? Yes ...... No ...... Usually ......

Any comments (for example, if you have occasional leaks, what provokes them:

The 13 patients entered as YY in column 6 of Table ticked 'yes' for diurnal and nocturnal continence and made no comment conflicting with this answer.

The 10 patients entered as YYQ in the same column ticked 'yes' for diurnal and nocturnal continence, but made a comment which indicated occasional leaks.

The 4 patients entered as UY, the one entered as YU and the 9 entered as UU ticked 'usually' for diurnal continence, nocturnal continence, or both respectively.

Two patients (entered as CATH) have long-term indwelling catheters. Nine patients, entered as NN, ticked 'no' for both diurnal and nocturnal continence. Four of them (patients 2, 11, 27, and 29) have had bladder neck resections, so their incontinence is to be expected. Patient 46 has reflex incontinence from insufficient 
deafferentation, and is on a waiting list for sacral posterior rhizotomy. Patient 9 is usually continent; his recent incontinence is being investigated. Patients 13 and 15 have been incontinent for a long time, but we are considering investigation and possible treatment. We are not involved in the care of patient 8 , and do not know why he is incontinent.

Reasons given for occasional leaks by patients in the YYQ, UY YU, and UU groups are excessive delay in using the implant ( 7 patients), bending forward ( 7 , of whom 3 specified that it caused leakage only if the bladder was very full); too much beer (2); too much of other drinks (3); full bowel (3); menstruation (2); urinary infection (2); lifting heavy objects (1); walking (1), and oversleeping (1). The majority of patients mentioned that the occasional leaks were of small volumes.

\section{Significant urinary infections}

The questions asked were:

How many urinary infections have you had in the last year in which

(a) You felt ill

(b) You were treated with antibiotics

Any comments

Of the 41 patients who use their implants, 29 reported no infections under (a) or (b). Of the patients who reported infections, the majority combined the (a) and (b) categories. Five patients reported one infection in the year. One patient reported two infections. Three patients reported three infections each. Three patients reported more than three infections each.

\section{Defaecation}

The questions asked were:

1. Do you use the stimulator to aid bowel function?

2. If so, has it enabled you to reduce the amount of time spent on bowel emptying?

3. Before you had your stimulator, did you do manual evacuation?

4. Do you do manual evacuation now?

5. Before you had your stimulator, did you take laxatives by mouth?

6. Do you take laxatives by mouth now?

7. Before you had your stimulator, did you use suppositories?

8. Do you use suppositories now?

The allowed answers for Questions 1 and 2 were 'yes' and 'no'. For questions 3 to 8 they were 'regularly', 'sometimes' or 'never'.

Twenty-seven of the 48 patients, shown by $\mathrm{Y}$ in column 7 of Table, use their implants for defaecation. Among the users, 21 said that the time spent on bowel emptying is reduced by the implant ( 1 adding the comment that the saving is very 
great). Five said that no time is saved, and 1 failed to indicate whether time is saved.

Questions 3 to 8 were answered by only 40 of the 48 patients, the others having received only an early form of the questionnaire lacking these questions. Ten patients (all users of their implants for defaecation) used manual evacuation less-either sometimes instead of regularly, or never instead of sometimes. The other 30 patients used manual evacuation to the same extent before the operation as after ( 22 regularly, 4 sometimes, 4 never). Four patients used aperients less postoperatively, and two patients used them more. Seven patients, all of whom used their implants for defaecation, ceased entirely to use suppositories. One non-user of the implant used suppositories less post-operatively, and 1 used them more. The other 31 patients did not change their suppository habit; 8 regularly used them before and after the operation, and 23 never used them.

\section{Erection}

Of the 37 surviving male patients, 13 reported getting full erections, and 3 partial erections by implant. Twenty-one reported no implant-driven erections. Of the 3 men who got partial erections, 2 used them as an aid to putting on condom urinals. Of the 13 getting full erections, 10 said that they used them for sexual intercourse (YY in the Table). The other 3 did not use them for any purpose, since they were continent and did not use condom urinals. (Column 8 of Table shows which men fell into each category).

\section{Implant failures}

Eighteen patients have had implant failures, some more than once (Table, Column 9, which shows the years in which failure occurred). In patient 1 , whose implant was never of practical use, the fault was discovered only when the receiver block was removed (and not replaced) 2 years after implantation. In patient 6 , the fault is in a channel of the implant that was not in use, so no repair has been needed. In patient 23, the fault could be seen in X-ray pictures to be a cable break in a place where repair would have been difficult, so a new sacral anterior root stimulator was implanted. In the remaining 15 patients, all the 23 known faults have been repaired, most often by replacing the receiver block and its connectors. Of these 23 faults, 6 were in receivers, 12 in connectors, and 5 in cables. The imperfections of design in the early receivers and connectors that caused the faults in the first 50 patients have now been corrected, and the mean implanted time per receiver or connector fault is greater for implants put in between July 1984 and December 1988 (6 such failures in 380 implant years) than for the implants of the present paper (18 such failures in 330 implant years). For cable failures there has been only an insignificant improvement; 6 such failures in 380 implant years for stimulators implanted between July 1984 and December 1988, as against 6 in 330 implant years for the implants of the present paper. A possible improvement in cable design is being tested.

\section{Side effects}

Patients were asked whether they presently had, formerly had, or had never had 
persisting side effects which they attributed to the implantation procedure or implant use. Certain side effects that might be expected were specifically enquired for (new back pain, discomfort in the region of the receiver block, increased spasticity or spasm, pain on using the stimulator, adverse changes in bowel function, increased sweating or other autonomic side effects). Patients were invited to give details of any such side effects, or to specify any side effects that they had which were not on our list.

One patient reported substantial backache, and 1 slight backache. Two noted occasional abdominal discomfort, and 1 recorded numbness and pain in the left arm (lesion at T5). Four patients had occasional twinges of discomfort around the receiver block. Seven noted increased spasms, mostly in the legs. Two non-users were unable to use their implant because of stimulus pain, while one user had mild pain. Four patients had noted increased constipation, likely to be related to sacral deafferentation.

Six patients had increased sweating below their lesion, 1 patient noted occasional headaches, and 1 (T3 lesion) had occasional autonomic dysreflexia on stimulation, not so severe as to prevent implant use. Only 1 man entered loss of reflex erections as a side effect in the questionnaire, though at least 8 men had told us on other occasions that they had lost their reflex erections. Probably, the others failed to mention it in the questionnaire because we had warned them before the operation that it was likely to follow the sacral posterior rhizotomy that they needed.

\section{Discussion}

This survey is a review of a group of patients whose progress up to 1985 has already been reported. ${ }^{11}$ It is of interest to examine their progress over four years.

In 1985, 43 to 49 surviving patients were used their implants for voiding, compared with 41 to 48 now; 2 others are awaiting repair. In the 1985 survey, 29 of 43 users were continent day and night, and 5 only by night; by 1989, 37 of 41 users were continent or nearly so by day and night. Frequency of use, incidence of side effects and number of symptomatic urinary infections were not directly addressed in the 1985 survey, so no direct comparison can be made. In 1985, only 'a few' patients used their implants to assist defaecation, and only 'one or two' no longer needed manual removal; by 1989, 25 of 41 users used their implant to assist defaecation; of these, 21 saved time by so doing, and 10 no longer needed to use manual removal. All these comparisons indicate at least no deterioration in implant performance; the great increase in use for bowel emptying is an advance, attributable to better understanding of the proper stimulus parameters for defaecation.

In contrast, the results for erection are alone in showing some probable deterioration. In 1985, 17 out of 33 male users reported full implant driven erections, and 6 others obtained partial erection, insufficient for coitus. In 1989, the figures were 13 out of 32, and 3, respectively; the man who died in 1989 had good implantdriven erections to the end.

\section{References}

1. BRINDLEY GS 1972 Electrode-arrays for making long-lasting electrical connexion to spinal roots. f Physiol 222:135-136. 
2. BRINDLEy GS 1973 Emptying the bladder by stimulating sacral ventral roots. F Physiol 237:15-156.

3. BRINDLEY GS 1977 An implant to empty the bladder or close the urethra. $\mathcal{F}$ Neurol Neurosurg Psychiatry 40:358-369.

4. BRindley GS, Polkey CE, Rushton DN 1982 Sacral anterior root stimulators for bladder control in paraplegia. Paraplegia 20:365-381.

5. Cardozo L, Krishnan KR, Polkey CE, Rushton DN, Brindley GS 1984 Urodynamic observations on patients with sacral anterior root stimulators. Paraplegia 22:201-209.

6. MADERSBACHER H, FisChER J, EBNER A 1988 Anterior sacral root stimulator (Brindley): experiences especially in women with neurogenic urinary incontinence. Neurology $\mathcal{E}$ Urodynamics 7:593-601.

7. BRINDLEY GS 1988 The actions of parasympathetic and sympathetic nerves in human micturition, erection and seminal emission, and their restoration in paraplegic patients by implanted electrical stimulators. Proc Roy Soc 235:111-120.

8. Egon G, Colombel P, des Roseaux F, Philippi R, Herlant M 1989 Electro-stimulation des racines sacrees anterieures chez le paraplegique. A propos de 13 observations. Annales de Readaptation et de Medicine Physique 32:47-57.

9. SCHMIDT RA 1986 Advances in genito-urinary neurostimulation. Neurosurgery 18:1041-1044.

10. TANAGHo EA, SChmidt RA, ORVIS BR 1989 Neural stimulation for control of voiding dysfunction: a preliminary report in 22 patients with serious neuropathic voiding disorders. $\mathcal{F}$ Urol 142:340-345.

11. Brindley GS, Polkey CE, Rushton DN, Cardozo L 1986 Sacral anterior root stimulator for bladder control in paraplegia: the first 50 cases. $f$ Neurol Neurosurg Psychiatry 49:1104-1114. 